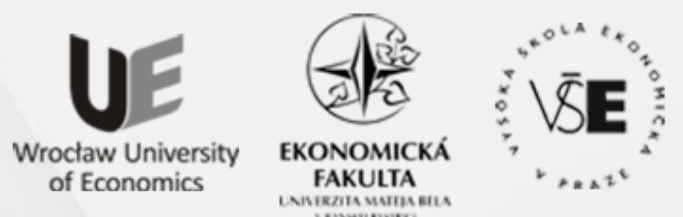

Conference Proceedings

Full TeXT PAPERS

edited by

Zofia Rusnak and Beata Zmyślona

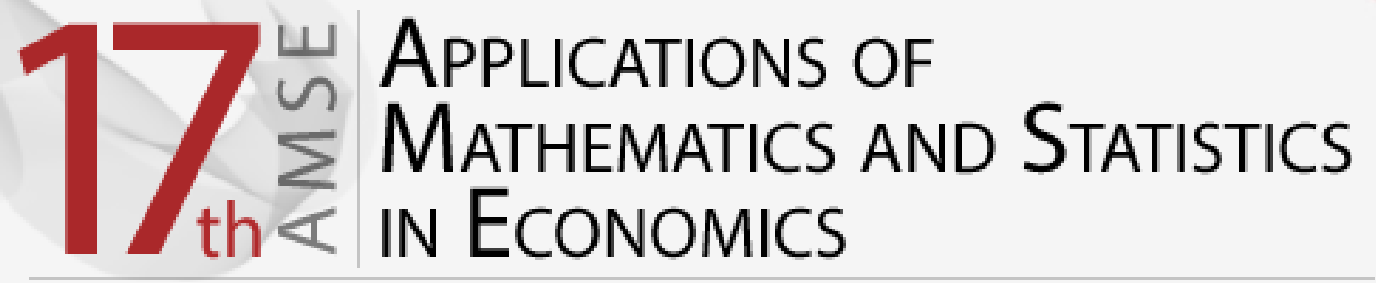

International Scientific Conference | Poland • 27-31 August 2014 
Scientific Committee

Richard Hindls, Stanislava Hronová, Rudolf Zimka, Walenty Ostasiewicz, Emília Zimková, Zofia Rusnak, Martin Bod'a

Organizing Committee

Beata Zmyślona, Cyprian Kozyra, Grzegorz Rogoziński, Kristýna Vltavská

\section{Reviewers}

Milan Bašta, Diana Bílková, Martin Bod'a, Joanna Dębicka, Tomáš Fiala, Jakub Fischer, Stanisław Heilpern, Karel Helman, Lenka Hudrlíková, Miroslav Hužvár, Nikola Kaspř́ková, Alena Kaščáková, Kamil Kladívko, Jindřich Klůfa, Pavol Král', Katarzyna Kuziak, Jana Langhamrová, Ivana Malá, Tomáš Marcinko, Luboš Marek, Miloš Maryška, Petr Mazouch, Zofia Mielecka-Kubień, Witold Miszczak, Petr Musil, Gabriela Nedelová, Walenty Ostasiewicz, Iva Pecáková, Viera Roháčová, Zofia Rusnak, Mária Stachová, Jana Špirková, Šárka Šustová, Jana Tepperová, Vladimír Úradníček, Kristýna Vltavská, Michal Vrabec, Dariusz Wawrzyniak, Henryk Zawadzki, Jaroslav Zbranek, Tomáš Zeithamer, Martin Zelený, Jan Zeman, Rudolf Zimka, Emília Zimková, Pavel Zimmermann, David Žižka

Layout

Martin Bod'a, Beata Zmyślona, Grzegorz Rogoziński

Front page design

Grzegorz Rogoziński

CD cover design

Beata Dębska

Articles published in the form submitted by the authors

All rights reserved. No part of this book may be reproduced in any form or in any means without the prior permission in writing of the Publisher

(C) Copyright by Wrocław University of Economics Wrocław 2014

ISBN 978-83-7695-421-9

Wydawnictwo Uniwersytetu Ekonomicznego we Wrocławiu

53-345 Wrocław, ul. Komandorska 118/120 www.ue.wroc.pl

Sprzedaż książek tel./fax 71 36-80-602

e-mail: econbook@ue.wroc.pl www.ksiegarnia.ue.wroc.pl 


\section{Contents}

Foreword

Diana Bílková: TL-Moments: Analogy of Classical L-Moments

Dagmar Blatná: Application of Robust Regression in the Analysis of Internet Access in European Countries

Martin Bod’a, Mária Kanderová: Rebalancing Issues in Tracking Error Variance Minimization

Martin Bod'a, Viera Roháčová: Application of Six Sigma Ideas to Timing Decisions at Financial Markets

Anton Dekrét, Rudolf Zimka: On the Price Hartwick's Task and Its Inverse in a Dynamic Model of an Economy with Exhaustible Resources

Joanna Dębicka, Agnieszka Marciniuk: Comparison of Reverse Annuity Contract and Reverse Mortgage on the Polish Market.

Petra Dotlačilová, Jitka Langhamrová: The Influence of Mortality Models for the Expected Future Life-time of Older People

Marek Ďurica, Lucia Švábová: Delta and Gamma for Chooser Options.

Vlastimil Farkašovský: New Concept of Pension Funds Performance Evaluation

Albert Gardon: The Normality of Weekly Relative Changes of the Freight Rate in Container Shipping.

Mária Grausová, Miroslav Hužvár, Jana Štrangfeldová: Healthcare Systems Efficiency in the Visegrád Group.

Stanisław Heilpern: Multiple Life Insurance - Pension Calculation

Alena Kaščáková, Gabriela Nedelová: Changes in Slovak Households' Economy

Igor Kollár, Pavol Král', Peter Laco: Methodology for Assessing Website Improvement in Corporate Environment.

Maciej Kostrzewski: Some Method of Detecting the Jump Clustering Phenomenon in Financial Time Series.

Cyprian Kozyra, Beata Zmyślona, Katarzyna Madziarska: Complementary Objective and Subjective Measures of Hospital Services Quality...

Pavol Král', Mária Stachová, Lukáš Sobíšek: Utilization of Repeatedly Measured Financial Ratios in Corporate Financial Distress Prediction in Slovakia

Ivana Malá: The Use of Finite Mixture Model for Describing Differences in Unemployment Duration

Lukáš Malec: Studying Economics and Tourism Industry Relations by Smooth Partial Least Squares Method Depending on Parameter. 
Tomáš Marcinko: Consequences of Assumption Violations Regarding Classical Location Tests.

Edyta Mazurek: The Income Tax Progression Depending on Social Insurance Contribution in Poland.

Petr Musil, Jana Kramulová, Jan Zeman: Regional Consumption Expenditures: An Important Starting Point for Regional Input-output Tables.

Katarzyna Ostasiewicz, Walenty Ostasiewicz: Good Life: From Political to Human Economy

Anna Sączewska-Piotrowska: Analysis of Poverty Transitions in Poland Using Multilevel Discrete-Time Event History Models

Martina Šimková, Petra Švarcová: Disadvantaged University Students in the Czech Republic.

Michal Široký: The Use of Short-term Business Statistics for Quarterly GDP Flash Estimates in the Czech Republic

Zdeněk Šulc, Hana Řezanková: Evaluation of Recent Similarity Measures for Categorical Data.

Lucia Švábová, Marek Ďurica: The Relationship Between the Finite Difference Method and Trinomial Trees

Kristýna Vltavská, Jaroslav Sixta: The Estimation of Final Consumption Expenditures

Lenka Vraná: Business Cycle Analysis: Tracking Turning Points

Janusz Wywiał: On Bayesian Testing in Auditing

Emília Zimková: Window Analysis of Supper-efficiency Change: Case of the Slovak Banking System ....

Beata Zmyślona: Statistical Modelling of the Impact of Diabetes on the Risk of Hospitalization 


\title{
TL-MOMENTS: ANALOGY OF CLASSICAL L-MOMENTS
}

\author{
DIANA BÍLKOVÁ \\ University of Economics, Prague; Faculty of Informatics and Statistics; Department of Statistics and \\ Probability; Sq. W. Churchill 1938/4; 13067 Prague 3; Czech Republic \\ email: bilkova@vse.cz
}

\begin{abstract}
Moments and cumulants are commonly used to characterize the probability distribution or observed data set. The use of the moment method of parameter estimation is also common in the construction of an appropriate parametric distribution for a certain data set. The moment method does not always produce satisfactory results. It is difficult to determine exactly what information concerning the shape of the distribution is expressed by its moments of the third and higher order. In the case of small samples in particular, numerical values of sample moments can be very different from the corresponding values of theoretical moments of the relevant probability distribution from which the random sample comes. Parameter estimations of the probability distribution made by the moment method are often considerably less accurate than those obtained using other methods, particularly in the case of small samples. The present paper deals with an alternative approach to the construction of an appropriate parametric distribution for the considered data set using order statistics.
\end{abstract}

Key words: L-moments and TL-moments of probability distribution, sample L-moments and TL-moments, order statistics.

DOI: 10.15611/amse.2014.17.01

\section{Introduction}

L-moments form the basis for a general theory which includes the summarization and description of theoretical probability distributions and obtained sample data sets, parameter estimation of theoretical probability distributions and hypothesis testing of parameter values for theoretical probability distributions. The theory of L-moments includes the established methods such as the use of order statistics and the Gini middle difference. It leads to some auspicious innovations in the area of measuring skewness and kurtosis of the distribution and provides relatively new methods of parameter estimation for an individual distribution. Lmoments can be defined for any random variable whose expected value exists. The main advantage of L-moments over conventional moments is that they can be estimated by linear functions of sample values and are more resistant to the influence of sample variability. Lmoments are more robust than conventional moments to the existence of outliers in the data, facilitating better conclusions made on the basis of small samples of the basic probability distribution. L-moments sometimes bring even more efficient parameter estimations of the parametric distribution than those acquired by the maximum likelihood method for small samples in particular.

L-moments have certain theoretical advantages over conventional moments consisting in the ability to characterize a wider range of the distribution. They are also more resistant and 
less prone to estimation bias, approximation by the asymptotic normal distribution being more accurate in finite samples.

Let $X$ be a random variable being distributed with the distribution function $F(x)$ and quantile function $x(F)$ and let $X_{1}, X_{2}, \ldots, X_{n}$ be a random sample of the sample size $n$ from this distribution. Then $X_{1: n} \leq X_{2: n} \leq \ldots \leq X_{n: n}$ are order statistics of the random sample of the sample size $n$ which comes from the distribution of the random variable $X$.

L-moments are analogous to conventional moments. They can be estimated on the basis of linear combinations of sample order statistics, i.e. L-statistics. L-moments are an alternative system describing the shape of the probability distribution.

\section{L-Moments of Probability Distributions}

The issue of L-moments is discussed, for example, in (Adamowski, 2000) or (Ulrych, 2000 ). Let $X$ be a continuous random variable being distributed with the distribution function $F(x)$ and quantile function $x(F)$. Let $X_{1: n} \leq X_{2: n} \leq \ldots \leq X_{n: n}$ be order statistics of a random sample of the sample size $n$ which comes from the distribution of the random variable $X$. Lmoment of the $r$-th order of the random variable $X$ is defined as

$$
\lambda_{r}=\frac{1}{r} \cdot \sum_{j=0}^{r-1}(-1)^{j} \cdot\left(\begin{array}{c}
r-1 \\
j
\end{array}\right) \cdot E\left(X_{r-j: r}\right), \quad r=1,2, \ldots
$$

An expected value of the $r$-th order statistic of the random sample of the sample size $n$ has the form

$$
E\left(X_{r: n}\right)=\frac{n !}{(r-1) ! \cdot(n-r) !} \cdot \int_{0}^{1} x(F) \cdot[F(x)]^{r-1} \cdot[1-F(x)]^{n-r} \mathrm{~d} F(x)
$$

If we substitute equation (2) into equation (1), after adjustments we obtain

$$
\lambda_{r}=\int_{0}^{1} x(F) \cdot P_{r-1}^{*}[F(x)] \mathrm{d} F(x), \quad r=1,2, \ldots,
$$

where

$$
P_{r}^{*}[F(x)]=\sum_{j=0}^{r} p_{r, j}^{*} \cdot[F(x)]^{j} \quad \text { a } \quad p_{r, j}^{*}=(-1)^{r-j} \cdot\left(\begin{array}{c}
r \\
j
\end{array}\right) \cdot\left(\begin{array}{c}
r+j \\
j
\end{array}\right),
$$

$P_{r}^{*}[F(x)]$ being the $r$-th shifted Legendre polynomial. Having substituted expression (2) into expression (1), we also obtained

$$
\lambda_{r}=\frac{1}{r} \cdot \sum_{j=0}^{r-1}(-1)^{j} \cdot\left(\begin{array}{c}
r-1 \\
j
\end{array}\right) \cdot \frac{r !}{(r-j-1) ! \cdot j !} \cdot \int_{0}^{1} x(F) \cdot[F(x)]^{r-j-1} \cdot[1-F(x)]^{j} \mathrm{~d} F(x), \quad r=1,2, \ldots
$$

The letter "L" in "L-moments" indicates that the $r$-th L-moment $\lambda_{r}$ is a linear function of the expected value of a certain linear combination of order statistics. The very estimation of 
the $r$-th L-moment $\lambda_{r}$, based on the obtained data sample, is thus the linear combination of order data values, i.e. L-statistics. The first four L-moments of the probability distribution are now defined as

$$
\begin{gathered}
\lambda_{1}=E\left(X_{1: 1}\right)=\int_{0}^{1} x(F) \mathrm{d} F(x), \\
\lambda_{2}=\frac{1}{2} E\left(X_{2: 2}-X_{1: 2}\right)=\int_{0}^{1} x(F) \cdot[2 F(x)-1] \mathrm{d} F(x), \\
\lambda_{3}=\frac{1}{3} E\left(X_{3: 3}-2 X_{2: 3}+X_{1: 3}\right)=\int_{0}^{1} x(F) \cdot\left\{6[F(x)]^{2}-6 F(x)+1\right\} \mathrm{d} F(x), \\
\lambda_{4}=\frac{1}{4} E\left(X_{4: 4}-3 X_{3: 4}+3 X_{2: 4}-X_{1: 4}\right)=\int_{0}^{1} x(F) \cdot\left\{20[F(x)]^{3}-30[F(x)]^{2}+12[F(x)]-1\right\} \mathrm{d} F(x) .
\end{gathered}
$$

The probability distribution can be specified by its L-moments even if some of its conventional moments do not exist, the opposite, however, is not true. It can be proved that the first L-moment $\lambda_{1}$ is a location characteristic, the second L-moment $\lambda_{2}$ being a variability characteristic. It is often desirable to standardize higher L-moments $\lambda_{r}, r \geq 3$, so that they can be independent of specific units of the random variable X. The ratio of L-moments of the $r$-th order of the random variable $X$ is defined as

$$
\tau_{r}=\frac{\lambda_{r}}{\lambda_{2}}, \quad r=3,4, \ldots
$$

We can also define the function of L-moments which is analogous to the classical coefficient of variation, i.e. the so called L-coefficient of variation

$$
\tau=\frac{\lambda_{2}}{\lambda_{1}}
$$

The ratio of L-moments $\tau_{3}$ is a skewness characteristic, the ratio of L-moments $\tau_{4}$ being a kurtosis characteristic of the corresponding probability distribution. Main properties of the probability distribution are very well summarized by the following four characteristics: L-location $\lambda_{1}$, L-variability $\lambda_{2}$, L-skewness $\tau_{3}$ and L-kurtosis $\tau_{4}$. L-moments $\lambda_{1}$ and $\lambda_{2}$, the L-coefficient of variation $\tau$ and ratios of L-moments $\tau_{3}$ and $\tau_{4}$ are the most useful characteristics for the summarization of the probability distribution. Their main properties are existence (if the expected value of the distribution exists, then all its L-moments exist) and uniqueness (if the expected value of the distribution exists, then L-moments define the only distribution, i.e. no two distributions have the same L-moments). More for example, see (Hosking, 1990) or (Hosking, 1997).

\section{Sample L-Moments}

L-moments are usually estimated by a random sample obtained from an unknown distribution. Since the $r$-th L-moment $\lambda_{r}$ is the function of the expected values of order statistics of a random sample of the sample size $r$, it is natural to estimate it using the socalled U-statistic, i.e. the corresponding function of sample order statistics (averaged over all 
subsets of the sample size $r$, which may be formed from the obtained random sample of the sample size $n$ ).

Let $x_{1}, x_{2}, \ldots, x_{n}$ be the sample and $x_{1: n} \leq x_{2: n} \leq \ldots \leq x_{n: n}$ the order sample. Then the $r$-th sample L-moment can be written as

$$
l_{r}=\left(\begin{array}{c}
n \\
r
\end{array}\right)^{-1} \sum_{1 \leq i 1<i 2<\ldots<i r \leq n} \sum_{r=0} \ldots \sum_{j} \cdot \sum_{j=0}^{r-1}(-1)^{j} \cdot\left(\begin{array}{c}
r-1 \\
j
\end{array}\right) \cdot x_{i r-j: n}, \quad r=1,2, \ldots, n
$$

Hence the first four sample L-moments have the form

$$
\begin{gathered}
l_{1}=\frac{1}{n} \cdot \sum_{i} x_{i}, \\
l_{2}=\frac{1}{2} \cdot\left(\begin{array}{l}
n \\
2
\end{array}\right)^{-1} \cdot \sum_{i>j}\left(x_{i: n}-x_{j: n}\right), \\
l_{3}=\frac{1}{3} \cdot\left(\begin{array}{l}
n \\
3
\end{array}\right)^{-1} \cdot \sum_{i>j>k}\left(x_{i: n}-2 x_{j: n}+x_{k: n}\right), \\
l_{4}=\frac{1}{4} \cdot\left(\begin{array}{l}
n \\
4
\end{array}\right)^{-1} \cdot \sum_{i>j>k>l}^{\sum \sum \sum}\left(x_{i: n}-3 x_{j: n}+3 x_{k: n}-x_{l: n}\right) .
\end{gathered}
$$

U-statistics are widely used especially in nonparametric statistics. Their positive properties are the absence of bias, asymptotic normality and a slight resistance due to the influence of outliers.

When calculating the $r$-th sample L-moment, it is not necessary to repeat the process over all sub-sets of the sample size $r$, since this statistic can be expressed directly as a linear combination of order statistics of a random sample of the sample size $n$.

If we assume an estimate of $E\left(X_{r: r}\right)$ obtained with the use of U-statistics, it can be written as $r \cdot b_{r-1}$, where

$$
b_{r}=\frac{1}{n} \cdot\left(\begin{array}{c}
n-1 \\
r
\end{array}\right)^{-1} \cdot \sum_{j=r+1}^{n}\left(\begin{array}{c}
j-1 \\
r
\end{array}\right) \cdot x_{j: n}
$$

namely

$$
\begin{gathered}
b_{0}=\frac{1}{n} \cdot \sum_{j=1}^{n} x_{j: n}, \\
b_{1}=\frac{1}{n} \cdot \sum_{j=2}^{n} \frac{(j-1)}{(n-1)} \cdot x_{j: n},
\end{gathered}
$$




\section{$17 \backsim$ APPLICATIONS OF

$$
b_{2}=\frac{1}{n} \cdot \sum_{j=3}^{n} \frac{(j-1) \cdot(j-2)}{(n-1) \cdot(n-2)} \cdot x_{j: n}
$$

and so generally

$$
b_{r}=\frac{1}{n} \cdot \sum_{j=r+1}^{n} \frac{(j-1) \cdot(j-2) \cdot \ldots \cdot(j-r)}{(n-1) \cdot(n-2) \cdot \ldots \cdot(n-r)} \cdot x_{j: n} .
$$

Thus the first sample L-moments can be written as

$$
\begin{gathered}
l_{1}=b_{0}, \\
l_{2}=2 b_{1}-b_{0}, \\
l_{3}=6 b_{2}-6 b_{1}+b_{0}, \\
l_{4}=20 b_{3}-30 b_{2}+12 b_{1}-b_{0} .
\end{gathered}
$$

We can therefore write generally

$$
l_{r+1}=\sum_{k=0}^{r} p_{r, k}^{*} b_{k}, \quad r=0,1, \ldots, n-1,
$$

where

$$
p_{r, k}^{*}=(-1)^{r-k} \cdot\left(\begin{array}{l}
r \\
k
\end{array}\right) \cdot\left(\begin{array}{c}
r+k \\
k
\end{array}\right)=\frac{(-1)^{r-k} \cdot(r+k) !}{(k !)^{2} \cdot(r-k) !} .
$$

Sample L-moments are used in a similar way as sample conventional L-moments, summarizing the basic properties of the sample distribution, which are the location (level), variability, skewness and kurtosis. Thus, sample L-moments allow an estimation the corresponding properties of the probability distribution from which the sample originates and can be used in estimating the parameters of the relevant probability distribution. We often prefer L-moments to conventional moments within such applications, since sample Lmoments - as the linear functions of sample values - are less sensitive to sample variability or measurement errors in extreme observations than conventional moments. L-moments therefore lead to more accurate and robust estimates of characteristics or parameters of the basic probability distribution.

Sample L-moments have been used previously in statistics, but not as part of a unified theory. The first sample L-moment $l_{1}$ is a sample L-location (sample average), the second sample L-moment $l_{2}$ being a sample L-variability. The natural estimation of L-moments (10) ratio is the sample ratio of L-moments

$$
t_{r}=\frac{l_{r}}{l_{2}}, \quad r=3,4, \ldots
$$


Hence $t_{3}$ is a sample L-skewness and $t_{4}$ is a sample L-kurtosis. Sample ratios of L-moments $t_{3}$ and $t_{4}$ may be used as the characteristics of skewness and kurtosis of a sample data set.

The Gini middle difference relates both to sample L-moments, having the form of

$$
\left.G=\left(\begin{array}{l}
n \\
2
\end{array}\right)^{-1} \cdot \sum_{i>j} \sum_{i: n}-x_{j: n}\right)
$$

and the Gini coefficient which depends only on a single parameter $\sigma$ in the case of the twoparametric lognormal distribution, depending, however, on the values of all three parameters in the case of the three-parametric lognormal distribution. More for example in (Elamir, 2003).

\section{TL-Moments of Probability Distributions}

An alternative robust version of L-moments is introduced in this subchapter. The modification is called "trimmed L-moments" and it is termed TL-moments. The expected values of order statistics of a random sample in the definition of L-moments of probability distributions are replaced with those of a larger random sample, its size growing correspondingly to the extent of the modification, as shown below.

Certain advantages of TL-moments outweigh those of conventional L-moments and central moments. TL-moment of the probability distribution may exist despite the non-existence of the corresponding L-moment or central moment of this probability distribution, as it is the case of the Cauchy distribution. Sample TL-moments are more resistant to outliers in the data. The method of TL-moments is not intended to replace the existing robust methods but rather supplement them, particularly in situations when we have outliers in the data.

In this alternative robust modification of L-moments, the expected value $E\left(X_{r-j: r}\right)$ is replaced with the expected value $E\left(X r+t_{1}-j: r+t_{1}+t_{2}\right)$. Thus, for each $r$, we increase the sample size of a random sample from the original $r$ to $r+t_{1}+t_{2}$, working only with the expected values of these $r$ modified order statistics $X t_{1}+1: r+t_{1}+t_{2}, X t_{1}+2: r+t_{1}+t_{2}$, $\ldots, X t_{1}+r: r+t_{1}+t_{2}$ by trimming the smallest $t_{1}$ and largest $t_{2}$ from the conceptual random sample. This modification is called the $r$-th trimmed L-moment (TL-moment) and marked as $\lambda_{r}^{\left(t 1, t_{2}\right)}$. Thus, TL-moment of the $r$-th order of the random variable $X$ is defined as

$$
\lambda_{r}^{\left(t 1, t_{2}\right)}=\frac{1}{r} \cdot \sum_{j=0}^{r-1}(-1) j \cdot\left(\begin{array}{c}
r-1 \\
j
\end{array}\right) \cdot E\left(X_{r+t_{1}-j: r+t_{1}+t_{2}}\right), \quad r=1,2, \ldots
$$

It is evident from the expressions (30) and (1) that TL-moments are reduced to L-moments, where $t_{1}=t_{2}=0$. Although we can also consider applications where the adjustment values are not equal, i.e. $t_{1} \neq t_{2}$, we will focus here only on the symmetric case $t_{1}=t_{2}=t$. Then the expression (30) can be rewritten

$$
\lambda_{r}^{(t)}=\frac{1}{r} \cdot \sum_{j=0}^{r-1}(-1)^{j} \cdot\left(\begin{array}{c}
r-1 \\
j
\end{array}\right) \cdot E\left(X_{r+t-j: r+2 t}\right), \quad r=1,2, \ldots .
$$


Thus, for example, $\lambda_{1}^{(t)}=E\left(X_{1+t: 1+2 t}\right)$ is the expected value of the median of the conceptual random sample of $1+2 t$ size. It is necessary to note that $\lambda_{1}^{(t)}$ is equal to zero for distributions that are symmetrical around zero.

For $t=1$, the first four TL-moments have the form

$$
\begin{gathered}
\lambda_{1}^{(1)}=E\left(X_{2: 3}\right), \\
\lambda_{2}^{(1)}=\frac{1}{2} E\left(X_{3: 4}-X_{2: 4}\right), \\
\lambda_{3}^{(1)}=\frac{1}{3} E\left(X_{4: 5}-2 X_{3: 5}+X_{2: 5}\right), \\
\lambda_{4}^{(1)}=\frac{1}{4} E\left(X_{5: 6}-3 X_{4: 6}+3 X_{3: 6}-X_{2: 6}\right) .
\end{gathered}
$$

The measurements of location, variability, skewness and kurtosis of the probability distribution analogous to conventional L-moments (6)-(9) are based on $\lambda_{1}^{(1)}, \lambda_{2}^{(1)}, \lambda_{3}^{(1)}$ a $\lambda_{4}^{(1)}$.

The expected value $E\left(X_{r: n}\right)$ can be written using the formula (2). With the use of the equation (2), we can express the right side of the equation (31) again as

$$
\lambda_{r}^{(t)}=\frac{1}{r} \cdot \sum_{j=0}^{r-1}(-1)^{j} \cdot\left(\begin{array}{c}
r-1 \\
j
\end{array}\right) \cdot \frac{(r+2 t) !}{(r+t-j-1) ! \cdot(t+j) !} \cdot \int_{0}^{1} x(F) \cdot[F(x)]^{r+t-j-1} \cdot[1-F(x)]^{t+j} \mathrm{~d} F(x), r=1,2, \ldots
$$

It is necessary to point out that $\lambda_{r}^{(0)}=\lambda_{r}$ represents a normal $r$-th L-moment with no respective adjustments.

Expressions (32)-(35) for the first four TL-moments $(t=1)$ may be written in an alternative way as

$$
\begin{gathered}
\lambda_{1}^{(1)}=6 \cdot \int_{0}^{1} x(F) \cdot[F(x)] \cdot[1-F(x)] \mathrm{d} F(x), \\
\lambda_{2}^{(1)}=6 \cdot \int_{0}^{1} x(F) \cdot[F(x)] \cdot[1-F(x)] \cdot[2 F(x)-1] \mathrm{d} F(x), \\
\lambda_{3}^{(1)}=\frac{20}{3} \cdot \int_{0}^{1} x(F) \cdot[F(x)] \cdot[1-F(x)] \cdot\left\{5[F(x)]^{2}-5 F(x)+1\right\} \mathrm{d} F(x), \\
\lambda_{4}^{(1)}=\frac{15}{2} \cdot \int_{0}^{1} x(F) \cdot[F(x)] \cdot[1-F(x)] \cdot\left\{14[F(x)]^{3}-21[F(x)]^{2}+9[F(x)]-1\right] \mathrm{d} F(x) .
\end{gathered}
$$

The distribution can be determined by its TL-moments, even though some of its L-moments or conventional moments do not exist. For example, $\lambda_{1}^{(1)}$ (the expected value of the median of a conceptual random sample of sample size three) exists for the Cauchy distribution, despite the non-existence of the first L-moment $\lambda_{1}$. 


\section{$177^{2}$ Ant \\ Mathematics and Statistics \\ IN ECONOMICS}

TL-skewness $\tau_{3}^{(t)}$ and TL-kurtosis $\tau_{4}^{(t)}$ can be defined analogously as L-skewness $\tau_{3}$ and L-kurtosis $\tau_{4}$

$$
\begin{gathered}
\tau_{3}^{(t)}=\frac{\lambda_{3}^{(t)}}{\lambda_{2}^{(t)}}, \\
\tau_{4}^{(t)}=\frac{\lambda_{4}^{(t)}}{\lambda_{2}^{(t)}} .
\end{gathered}
$$

\section{Sample TL-Moments}

Let $x_{1}, x_{2}, \ldots, x_{n}$ be a sample and $x_{1: n} \leq x_{2: n} \leq \ldots \leq x_{n: n}$ an order sample. The expression

$$
\hat{E}\left(X_{j+1: j+l+1}\right)=\frac{1}{\left(\begin{array}{c}
n \\
j+l+1
\end{array}\right)} \cdot \sum_{i=1}^{n}\left(\begin{array}{c}
i-1 \\
j
\end{array}\right) \cdot\left(\begin{array}{c}
n-i \\
l
\end{array}\right) \cdot x_{i: n}
$$

is considered to be an unbiased estimate of the expected value of the $(j+1)$-th order statistic $X_{j+1: j+l+1}$ in the conceptual random sample of sample size $(j+l+1)$. Now we will assume that in the definition of TL-moment $\lambda_{r}^{(t)}$ in (31), the expression $E\left(X_{r+t-j: r+2 t}\right)$ is replaced by its unbiased estimate

$$
\hat{E}\left(X_{r+t-j: r+2 t}\right)=\frac{1}{\left(\begin{array}{c}
n \\
r+2 t
\end{array}\right)} \cdot \sum_{i=1}^{n}\left(\begin{array}{c}
i-1 \\
r+t-j-1
\end{array}\right) \cdot\left(\begin{array}{c}
n-i \\
t+j
\end{array}\right) \cdot x_{i: n},
$$

which is obtained by assigning $j \rightarrow r+t-j-1$ a $l \rightarrow t+j$ in (43). Now we get the $r$-th sample TL-moment

$$
\begin{gathered}
l_{r}^{(t)}=\frac{1}{r} \cdot \sum_{j=0}^{r-1}(-1)^{j} \cdot\left(\begin{array}{c}
r-1 \\
j
\end{array}\right) \cdot \hat{E}\left(X_{r+t-j: r+2 t}\right), \quad r=1,2, \ldots, n-2 t, \\
l_{r}^{(t)}=\frac{1}{r} \cdot \sum_{j=0}^{r-1}(-1)^{j} \cdot\left(\begin{array}{c}
r-1 \\
j
\end{array}\right) \cdot \frac{1}{\left(\begin{array}{c}
n \\
r+2 t
\end{array}\right)} \cdot \sum_{i=1}^{n}\left(\begin{array}{c}
i-1 \\
r+t-j-1
\end{array}\right) \cdot\left(\begin{array}{c}
n-i \\
t+j
\end{array}\right) \cdot x_{i: n}, \quad r=1,2, \ldots, n-2 t,
\end{gathered}
$$

which is an unbiased estimate of the $r$-th TL-moment $\lambda_{r}^{(t)}$. Let us note that for each $j=0,1, \ldots, r-1$, the values $x_{i: n}$ in (46) are not equal to zero only for $r+t-j \leq i \leq n-t-j$, taking combination numbers into account. A simple adjustment of equation (46) provides an alternative linear form

$$
l_{r}^{(t)}=\frac{1}{r} \cdot \sum_{i=r+t}^{n-t}\left[\frac{\sum_{j=0}^{r-1}(-1)^{j} \cdot\left(\begin{array}{c}
r-1 \\
j
\end{array}\right)\left(\begin{array}{c}
i-1 \\
r+t-j-1
\end{array}\right) \cdot\left(\begin{array}{c}
n-i \\
t+j
\end{array}\right)}{\left(\begin{array}{c}
n \\
r+2 t
\end{array}\right)}\right] \cdot x_{i: n} .
$$




\section{$17 \backsim$ APPLICATIONS OF \\ Mathematics and Statistics \\ IN ECONOMICS}

For $r=1$, for example, we obtain for the first sample TL-moment

$$
l_{1}^{(t)}=\sum_{i=t+1}^{n-t} w_{i: n}^{(t)} \cdot x_{i: n}
$$

where the weights are given by

$$
w_{i: n}^{(t)}=\frac{\left(\begin{array}{c}
i-1 \\
t
\end{array}\right) \cdot\left(\begin{array}{c}
n-i \\
t
\end{array}\right)}{\left(\begin{array}{c}
n \\
2 t+1
\end{array}\right)} .
$$

The above results can be used for the estimation of TL-skewness $\tau_{3}^{(t)}$ and TL-kurtosis $\tau_{4}^{(t)}$ by simple ratios

$$
\begin{aligned}
& t_{3}^{(t)}=\frac{l_{3}^{(t)}}{l_{2}^{(t)}}, \\
& t_{4}^{(t)}=\frac{l_{4}^{(t)}}{l_{2}^{(t)}} .
\end{aligned}
$$

We can choose $t=n \alpha$, representing the size of the adjustment from each end of the sample, where $\alpha$ is a certain ratio, where $0 \leq \alpha<0,5$.

\section{Results}

L-moments method used to be employed in hydrology, climatology and meteorology in the research of extreme precipitation, having mostly used smaller data sets. This study presents applications of L-moments and TL-moments to large sets of economic data. The research variable is the net annual household income per capita (in CZK) in the Czech Republic (nominal income). The data collected by the Czech Statistical Office come from the Mikrocenzus statistical investigation covering the years 1992, 1996 and 2002 and EU-SILC survey spanning the period 2004-2007. In total, 168 income distributions were analyzed - for all households in the Czech Republic as well as with the use of particular criteria: gender, region (Bohemia and Moravia), social group, municipality size, age and the highest educational attainment. With only minor exceptions, the TL-moments method produced the most accurate results. L-moments was the second most effective method in more than half of the cases, the differences between this method and that of maximum likelihood not being significant enough as far as the number of cases, when the former gave better results than the latter. Table 1 represents distinctive outcomes for all 168 income distributions, showing the results for the total household sets in the Czech Republic. Apart from the estimated parameter values of the three-parametric lognormal distribution, which were obtained having simultaneously employed TL-moments, L-moments and maximum likelihood methods, Table 1 contains the values of the test criterion $\chi^{2}$, indicating that the L-moments method produced in four out of seven cases - more accurate results than the maximum likelihood method, the most accurate outcomes in all seven cases being produced by the TL-moments method. 


\section{Am Ancranos of Mathematics and Statistics IN ECONOMICS \\ International Scientific Conference | Poland • 27-31 August 2014}

Table 1. Parameter estimations of three-parametric lognormal curves obtained using three various robust methods of point parameter estimation and the value of $\chi^{2}$ criterion

\begin{tabular}{|c|c|c|c|c|c|c|c|c|c|}
\hline \multirow[t]{2}{*}{ Year } & \multicolumn{3}{|c|}{ Method of TL-moments } & \multicolumn{3}{|c|}{ Method of L-moments } & \multicolumn{3}{|c|}{$\begin{array}{l}\text { Maximum likelihood } \\
\text { method }\end{array}$} \\
\hline & $\mu$ & $\sigma^{2}$ & $\theta$ & $\mu$ & $\sigma^{2}$ & $\theta$ & $\mu$ & $\sigma^{2}$ & $\theta$ \\
\hline 1992 & 9.722 & 0.521 & 14,881 & 9.696 & 0.700 & 14,491 & 10.384 & 0.390 & -325 \\
\hline 1996 & 10.334 & 0.573 & 25,981 & 10.343 & 0.545 & 25,362 & 10.995 & 0.424 & 52.231 \\
\hline 2002 & 10.818 & 0.675 & 40,183 & 10.819 & 0.773 & 37,685 & 11.438 & 0.459 & 73.545 \\
\hline 2004 & 10.961 & 0.552 & 39,899 & 11.028 & 0.675 & 33,738 & 11.503 & 0.665 & 7.675 \\
\hline 2005 & 11.006 & 0.521 & 40,956 & 11.040 & 0.677 & 36,606 & 11.542 & 0.446 & -8.826 \\
\hline 2006 & 11.074 & 0.508 & 44,941 & 11.112 & 0.440 & 40,327 & 11.623 & 0.435 & -42.331 \\
\hline 2007 & 11.156 & 0.472 & 48,529 & 11.163 & 0.654 & 45,634 & 11.703 & 0.421 & -171.292 \\
\hline Year & \multicolumn{3}{|c|}{ Criterion $\chi^{2}$} & \multicolumn{3}{|c|}{ Criterion $\chi^{2}$} & \multicolumn{3}{|c|}{ Criterion $\chi^{2}$} \\
\hline 1992 & \multicolumn{3}{|c|}{739.512} & \multicolumn{3}{|c|}{811.007} & \multirow{2}{*}{\multicolumn{3}{|c|}{$\begin{array}{l}1,227.325 \\
2,197.251\end{array}$}} \\
\hline 1996 & \multicolumn{3}{|c|}{$1,503.878$} & \multicolumn{3}{|c|}{$1,742.631$} & & & \\
\hline 2002 & \multirow{2}{*}{\multicolumn{3}{|c|}{$\begin{array}{l}998.325 \\
494.441\end{array}$}} & \multicolumn{3}{|c|}{$1,535.557$} & \multicolumn{3}{|c|}{$\begin{array}{l}2,197.251 \\
1,060.891\end{array}$} \\
\hline 2004 & & & & \multicolumn{3}{|c|}{866.279} & \\
\hline 2005 & \multicolumn{3}{|c|}{731.225} & \multicolumn{3}{|c|}{899.245} & \multicolumn{3}{|c|}{995.855} \\
\hline 2006 & \multicolumn{3}{|c|}{831.667} & \multirow{2}{*}{\multicolumn{3}{|c|}{$1,220.478$}} & \multicolumn{3}{|c|}{$1,067.789$} \\
\hline 2007 & \multicolumn{3}{|c|}{$1,050.105$} & & & & \multicolumn{3}{|c|}{$1,199.035$} \\
\hline
\end{tabular}

Source: Own research

\section{Conclusion}

A relatively new class of moment characteristics of probability distributions has been introduced in the present paper. They are the characteristics of the location (level), variability, skewness and kurtosis of probability distributions constructed with the use of L-moments and TL-moments that represent a robust extension of L-moments. The very L-moments were implemented as a robust alternative to classical moments of probability distributions. Lmoments and their estimates, however, are lacking in some robust features that are associated with TL-moments.

\section{References}

1 ADAMOWSKI, K. 2000. Regional Analysis of Annual Maximum and Partial Duration Flood Data by Nonparametric and L-moment Methods. In Journal of Hydrology, 2000, vol. 229, iss. 3-4, pp. 219-231. ISSN 0022-1694.

2 ELAMIR, E. A. H., SEHEULT, A. H. 2003. Trimmed L-Moments. In Computational Statististics \& Data Analysis, 2003, vol. 43, iss. 3, pp. 299-314. ISSN 0167-9473.

3 HOSKING, J. R. M. 1990. L-moments: Analysis and Estimation of Distributions Using Linear Combinations of Order Statistics. In Journal of the Royal Statistical Society (Series B), 1990, vol. 52, iss. 1, pp. 105-124. ISSN 1467-9868.

4 HOSKING, J. R. M., WALLIS, J. R. 1997. Regional Frequency Analysis: An Approach Based on L-Moments. First ed. New York: Cambridge University Press, 1997, 209 p. ISBN 978-0521-43045-6.

5 ULRYCH, T. J., VELIS, D. R., WOODBURY, A. D., SACCHI, M. D. 2000. L-moments and C-moments. In Stochastic Environmental Research and Risk Assessment, 2000, vol. 14, pp. 50-68. ISSN 1436-3240. 